\title{
Personality and fruit and vegetable consumption in young men: qualitative and quantitative assessment
}

\author{
S. Howard Wilsher \\ ${ }^{1}$ University of Kent, Canterbury, Kent CT2 7TZ, UK
}

Increasing, but limited, evidence suggests personality plays a role in health behaviours. The Five Factor Model (FFM) incorporates five dimensions of personality: extraversion, agreeableness conscientiousness, emotional stability and openness to experience ${ }^{(1)}$. Boys $(6-12)$ scoring high on conscientious and emotionally stable consumed more fruit and vegetables, while those scoring low on these dimensions were more likely to be obese ${ }^{(2)}$. Likewise, highly conscientious students were more likely to adhere to healthy behaviours, including fruit and vegetable consumption (FVC), whereas highly extraverted students tended to adopt unhealthy behaviours ${ }^{(3)}$. Indeed a systematic review found conscientiousness traits were positively associated with all preventive health behaviours and negatively associated with unhealthy behaviours ${ }^{(4)}$. Despite the 5 a day campaign average FVC in the UK is still three portions per day, with young men consuming the least (2.9 portions). Little research has focussed on young men, but when older, men are at greater risk of early morbidity. The aim of the research was to assess whether personality of young men (18-24) may impact on their FVC. Such research is important for design of successful interventions to improve FVC and health in older age.

A purposive sample of eight young men (18-24) completed the ten item personality inventory (TIPI) ${ }^{(5)}$ and an interview on food choice. Four young men consumed four or more portions of fruit and vegetables daily and four consumed less than two portions daily. Each group contained a brother still living at home, each with different FVC. Food diaries and 24 hour recalls assessed FVC and interviews were thematically analysed into the five personality dimensions.

Of the five dimensions extraversion, agreeableness and openness to experiences failed to show any real difference between high and low FVC. However, conscientiousness and emotional stability presented an almost perfect result: high scores for high consumers and low scores for low consumers with support from the findings of the interviews. The personalities of the two brothers conformed to that norm. A low consumer overturned the trend on the personality dimensions; however, analysis of his interview did not support his TIPI scores. The scores may reflect the young man's drive for fitness rather than health. The findings replicate those of other studies on personality and health behaviours. More research is needed but if personality underlies health behaviours such as FVC, then interventions such as cognitive behaviour therapy may be more effective than behavioural interventions, with a need for individualized rather than generalized health messages.

The Agriculture and Horticulture Development Board funded the research.

1. Costa PT \& McCrae RR (1992) NEO PI-R professional manual. Florida: Odessa.

2. Vollrath ME, Hampson SE, Juliusson PB. Appetite. [2012 Jun;58(3), 1113-7.

3. Raynor D \& Levine H (2009) $J$ Am Coll Health. 58(1), 73-81.

4. Bogg T \& Roberts BW. Psychological Bulletin. 2004 Nov;130(6), 887-919.

5. Gosling S, Rentfrow PJ \& Swann WB, Jr. (2003) J Res Pers. 37, 504-28. 